\title{
Experimental Investigation of the Effect of Geogrid Reinforced Backfill Compaction on Buried Pipelines Response
}

\author{
Emran Alotaibi ${ }^{1}$, Maher Omar ${ }^{1}$, Mohamed G. Arab ${ }^{1,2}$, Abdallah Shanableh ${ }^{1}$, Waleed Zeiada ${ }^{1}$, Ali \\ Tahmaz ${ }^{1}$ \\ ${ }^{1}$ Department of Civil and Environmental Engineering, College of Engineering, University of Sharjah \\ Sharjah, Sharjah, UAE \\ U16200658@sharjah.ac.ae ; momar@sharjah.ac.ae; marab@sharjah.ae.ac; atahmaz@sharjah.ae.ac; \\ wzeiada@sharjah.ac.ae; shanableh@sharjah.ac.ae \\ ${ }^{2}$ Structural Engineering Department, Mansoura University \\ Al-Gomhoria Street, Mansoura, Egypt
}

\begin{abstract}
The increasing in development and population, have made using of shallow buried pipelines inevitable in highways, subways, and urban areas. In this paper the behavior and the response of shallow Polyvinyl chloride (PVC) pipes buried in geogrid reinforced sand under static loads was investigated. Three series of large-scale laboratory experiments were conducted under static loading. The first test program investigated the effect of compaction effort on the bearing capacity and surface settlement under static loading of strip footing with no buried pipe. In this testing program six levels of sand relative density were achieved $(30 \%, 40 \%, 50 \%, 60 \%, 70 \%$ and $80 \%)$. The tests results have shown significant improvement on bearing capacity of soil with decrease in surface settlement. In the second series, a buried PVC pipe with a diameter of $200 \mathrm{~mm}$ at a depth of $300 \mathrm{~mm}$ was in introduced and loaded with strip loading. In this series of testing the backfill relative density was changed over the same range. The increase in relative density have showed noticeable decrease in surface settlement and load transferred to the pipe crown. Third test series conducted with geogrid-reinforced backfill varying compaction effort above and below the geogrid reinforcement. The highest results have shown the importance of the compaction effort on the installation of geogrid reinforcement. The backfill reinforced with geogrid at relative density of $70 \%$ has shown a $78 \%$ reduction in surface settlement, while highest improvement of pipe crown deflection was $51 \%$ for $50 \%$ relative density. Also, optimum location of one layer of geogrid reinforcement has been investigated. The optimum depth to diameter ratio of the geogrid was found to be 0.11 regardless of the relative density.
\end{abstract}

Keywords: Buried Pipelines, Relative Densities, PVC Pipe Deflection, geogrid.

\section{Introduction}

Buried pipelines are usually used to transport water, natural gas and others. They are classified as lifelines, as they carry essential substances for human life [1]. The significance of pipelines breakage is considered economic, technical, and social. Many researchers focused on ways to protect the buried Polyvinyl chloride (PVC) pipes under different types of loading conditions. However, little work has been found on the effect of the relative density of the backfill on the performance of the buried lines. Rogers [2] studied the influence of installations procedure on the performance of a flexible buried pipelines, the results of testing four types of pipe installation conditions indicated that pipes placed in loose sand had lower vertical diametral strain and higher settlement than in dense sand, with clear correlation between both parameters. Sargand [3] investigated the effect of sand relative densities on arching of buried pipe, concluding that arching became more obvious as the relative density of the backfill increased. Using geosynthetics reinforcement could reduce settlement of foundation and enhance the bearing capacities foundation beds [4-7]. Several researchers have studied the behaviour, of pipes embedded beneath geogrid reinforced soil, under surface loading [8-10].

Moghaddas et al. [11] investigated the behavior of HDPE pipes buried in reinforced sand and subjected to cyclic loading, on different relative densities and variable number of reinforcement layers. They concluded that surface settlement of the backfill has been reduced by $51 \%$ using 5 layers of reinforcement, on dense sand, and reduction in vertical deflection of pipe with $40 \%$. However, such combination results of relative densities, reinforcement optimization, and their effect on a pipeline protection, is still unclear and need further investigations to understand the combined behavior and maximize their benefits. 


\section{Materials}

The model tests were carried out using available equipment at Civil and Environmental Engineering laboratories, University of Sharjah, United Arab Emirates. The test program and procedures of laboratory model are discussed below.

\subsection{Soil}

Sand used is known as "Beach Sand", was ordered from a quarry site, located $35 \mathrm{~km}$ south west from University of Sharjah. The results of routine soil testing conducted on a representative oven-dried sample presented in Table 1. The sand had $0.6 \%$ fines and no gravel particles, the soil is classified as poorly graded sand (SP) as per Unified Soil Classification System (USCS). Friction angle for dry soil conducted using direct shear test apparatus according to ASTM D3080, at six levels of relative density provided in Table 1.

Table 1: Soil Properties.

\begin{tabular}{|c|c|c|c|c|c|c|c|}
\hline Property & \multicolumn{6}{|c|}{ Value } & Method \\
\hline Specific Gravity, $G_{S}$ & \multicolumn{6}{|c|}{2.64} & $\begin{array}{c}\text { ASTM D854 } \\
{[12]}\end{array}$ \\
\hline Maximum dry density, $\gamma_{d \max }\left(\mathrm{kN} / \mathrm{m}^{3}\right)$ & \multicolumn{6}{|c|}{19.07} & \multirow{2}{*}{ ASTM [13] } \\
\hline Maximum Void Ratio, $e_{\min }$ & \multicolumn{6}{|c|}{0.360} & \\
\hline Minimum dry density, $\gamma_{d \min }\left(\mathrm{kN} / \mathrm{m}^{3}\right)$ & \multicolumn{6}{|c|}{15.06} & \multirow{2}{*}{$\begin{array}{c}\text { ASTM D4254 } \\
{[14]} \\
\end{array}$} \\
\hline Maximum Void Ratio, $e_{\max }$ & \multicolumn{6}{|c|}{0.720} & \\
\hline Effective particle size, $D_{10}(\mathrm{~mm})$ & \multicolumn{6}{|c|}{0.17} & \multirow{5}{*}{$\begin{array}{c}\text { ASTM D6913 } \\
{[15]}\end{array}$} \\
\hline$D_{60}(\mathrm{~mm})$ & \multicolumn{6}{|c|}{0.32} & \\
\hline$D_{30}(\mathrm{~mm})$ & \multicolumn{6}{|c|}{0.23} & \\
\hline Coefficient of uniformity, $C_{u}$ & \multicolumn{6}{|c|}{1.88} & \\
\hline Coefficient of curvature, $C_{c}$ & \multicolumn{6}{|c|}{0.97} & \\
\hline Soil classification as per USCS & \multicolumn{6}{|c|}{ SP } & $\begin{array}{c}\text { ASTM D2487 } \\
{[16]}\end{array}$ \\
\hline Relative density used, $D R(\%)$ & $30 \%$ & $40 \%$ & $50 \%$ & $60 \%$ & $70 \%$ & $80 \%$ & $\begin{array}{c}\text { ASTM D4254 } \\
{[14]}\end{array}$ \\
\hline Friction angle, $\varnothing\left(^{\circ}\right)$ & 30.9 & 32.7 & 34.2 & 36.4 & 38.5 & 41.1 & $\begin{array}{c}\text { ASTM D3080 } \\
{[17]}\end{array}$ \\
\hline
\end{tabular}

\subsection{PVC Pipe}

A high-pressure $200 \mathrm{~mm}$ PVC pipe of $3.2 \mathrm{~mm}$ wall thickness and modulus of elasticity (E) of $2.77 \mathrm{GPa}$ was used in current study. The PVC pipe is commercially available pipe that usually used for water supply, irrigation, and drainage in the local UAE market.

\subsection{Geogrid Reinforcement}

The geogrid used in this study is hexagonal geogrid structure consisting of high strength junctions and stiff ribs forming equilateral triangular apertures. The geogrid manufactured from a punched and drawn process of polypropylene sheet, which is then oriented in three equilateral directions. Geogrid used denoted as TriAx-150 geogrid, have the following engineering and physical properties according to the manufacturer: mass per unit area $=205 \mathrm{~g} / \mathrm{m}^{2}$, distance between alternate parallel ribs (hexagon) $=80 \mathrm{~mm}$, secant stiffness's are 250 and $360 \mathrm{kN} / \mathrm{m}$ at 2.0 and $0.5 \%$ strain, respectively. 


\section{Testing Apparatus and Testing Program}

\subsection{Testing Apparatus}

A steel braced sand box with dimensions of $2.1 \mathrm{~m}$ length, $0.8 \mathrm{~m}$ width and $0.9 \mathrm{~m}$ height, was used for conducting the experimental program as shown in Fig. 1. A reaction frame constructed along with the sand box, both supported by griddedI beams base, to withstand loading and moments.

\subsection{Preparation of the Physical Model}

In order to maintain experimental accuracy and repeatability of the testing conditions a procedure was developed to compact the soil backfill and bedding in the steel box. The bedding of buried pipe was compacted first with a vibratory compactor. The bedding soil was compacted to reach a relative compaction of $97 \%$. The uniformity of the compaction was checked using sand cone test at several depths of the compaction. The backfill above the pipe level was divided into three layers with thickness layers of $10 \mathrm{~cm}$ each. The backfill was compacted by tamping with rigid steel plate to required densities as illustrated in Table 2. Sand surface was levelled after backfilling, and footing with dimensions of $75 \times 750 \mathrm{~mm}$ was centered exactly beneath the $100 \mathrm{kN}$ capacity actuator. The footing is considered strip footing with plane strain loading as the width of the footing is about the same width of the steel box of about $800 \mathrm{~mm}$, which leaves $25 \mathrm{~mm}$ from each side to avoid direct friction of the footing with the wall. The strip footing consists of a rigid $40 \mathrm{~mm}$ thick steel plate, fixed to $70 \mathrm{~mm}$ wooden plate of same dimensions. A sand was glued to the base of the wooden base to enhance the interaction between the wooden base and sand backfill.

Two displacement transducers were placed on footing edges with equal distances from center, to ensure the uniformity of loading and to ensure the application of the load at the center of the footing. The loading was applied using the actuator controlled remotely using personal computer (PC). The rate of application was maintained at $0.05 \mathrm{~mm}$ per second. Pressure cells were used to monitor stresses at the locations shown in Fig.1 and 2. The deformation of the pipe is monitored using two linear variable differential transducers (LVDTs) as shown in Fig. 1. The load is applied at the soil surface till failure reached. After failure reached due to excessive settlement or tilting of footing, the test was stopped. The actuator then raised, footing and LVDTs removed and sand was removed, and the same methodology was repeated to compact the backfill soil to ensure repeatability. Fig. 2 shows a cross-section at the middle of the steel box that shows the details of the test setup and dimensions of the geogrid and the location of the buried pipe.

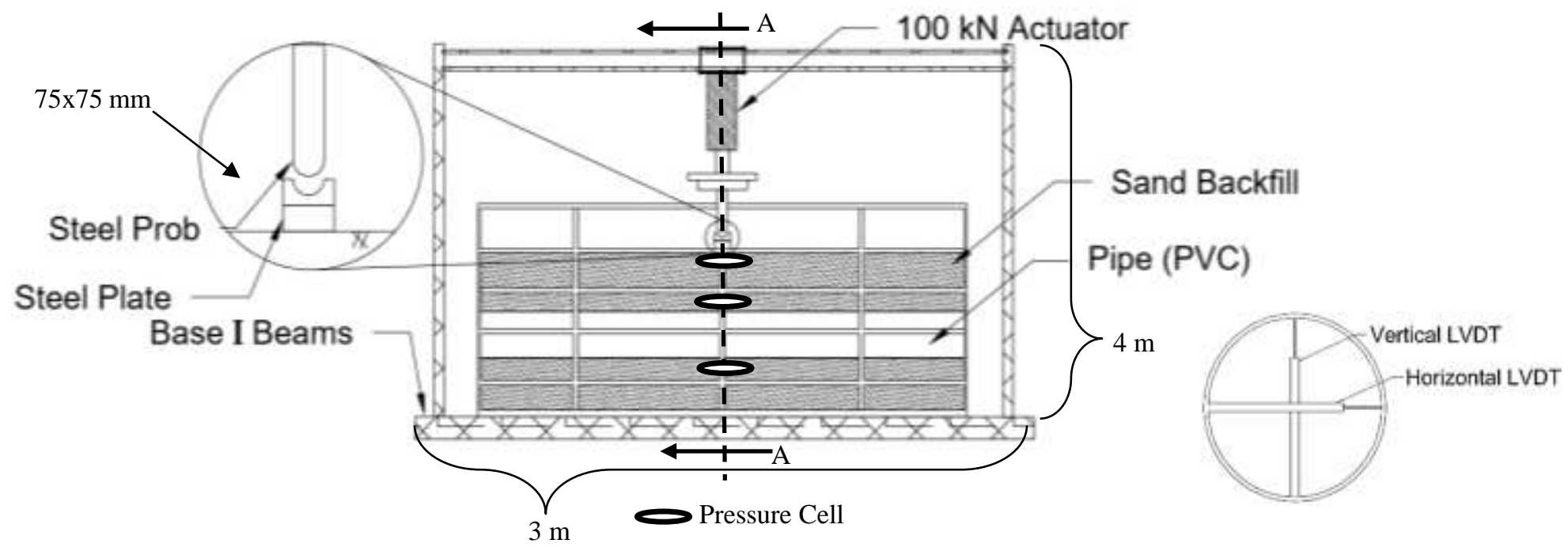

Fig. 1: Test Setup Sand box and pipes cross-section. 


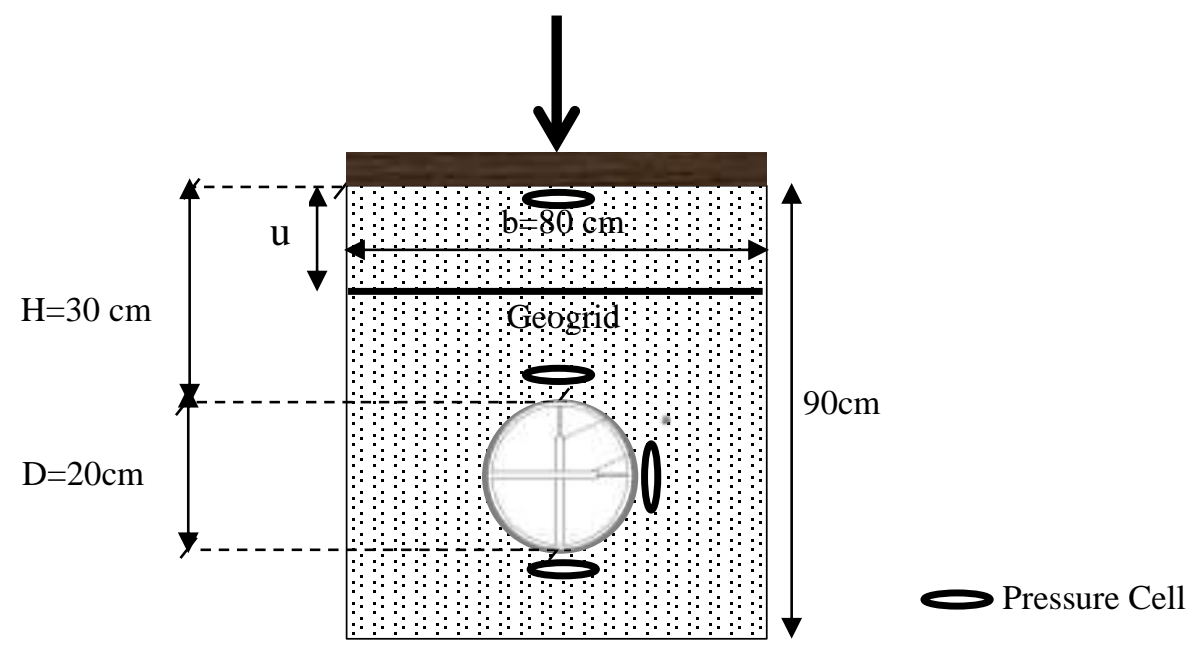

Fig. 2: Section A-A for the test plan setup.

\subsection{Testing program}

Three series of testing were conducted in this testing program. In the first set of testing backfill soil was compacted above the level of buried pipe bedding with no pipe nor geogrid reinforcement introduced. This testing series was used to ensure repeatability of the testing procedure proposed and validate the compaction procedure. As shown in Table 2 the test was conducted at several relative densities ranging from $30 \%$ to $80 \%$. Each test was repeated twice to ensure the reparability of the test. In the second series of the testing program a buried PVC pipe was introduced at a depth of $300 \mathrm{~mm}$ as shown in Fig.2 with no geogrid. This testing program will serve as a control for the geogrid reinforced backfill. Finally, geogrid reinforcement was introduced at a depth ranging from $1.5 \mathrm{~cm}$ to $3 \mathrm{~cm}$. Horizontal and vertical displacement transducers were placed inside the 2.1-m (10 D) pipe mid-length. The geogrid was extended over the whole width of the tested section with a width of $80 \mathrm{~cm}$ and length of $210 \mathrm{~cm}$ as shown in Fig. 1 and 2. The geometry and the variables introduced in this testing program is illustrated in Table 2.

Table 2: Experimental plan of the study.

\begin{tabular}{|l|c|c|c|l|}
\hline \multicolumn{1}{|c|}{ Test series } & Pipe & Geogrid & Variables & \multicolumn{1}{c|}{ Constants } \\
\hline Series 1: Six Tests & No & No & $\mathrm{DR}^{1}: 30 \%, 40 \%, 50 \%, 60 \%, 70 \%$ and $80 \%$ & $\mathrm{~B}^{2}=0.375 \mathrm{D}^{4}$ \\
\hline Series 2: Six Tests & Yes & No & $\mathrm{DR}^{1}: 30 \%, 40 \%, 50 \%, 60 \%, 70 \%$ and $80 \%$ & $\begin{array}{l}\mathrm{B}^{2}=0.375 \mathrm{D}^{4} \\
\mathrm{H}^{3}=1.5 \mathrm{D}^{4} \\
\mathrm{PL}^{5}=10 \mathrm{D}^{4}\end{array}$ \\
\hline Series 3: Nine Tests & Yes & Yes & $\begin{array}{l}\mathrm{DR}^{1}: 50 \%, 60 \% \text { and } 70 \% \\
\mathrm{u}^{7} / \mathrm{D}^{4}=0.075,0.113,0.15\end{array}$ & $\begin{array}{l}\mathrm{B}^{2}=0.375 \mathrm{D}^{4} \\
\mathrm{H}^{3}=1.5 \mathrm{D}^{4} \\
\mathrm{PL}^{5}=\mathrm{L}^{6}=10 \mathrm{D}^{4}\end{array}$ \\
\hline
\end{tabular}

${ }^{1} \mathrm{DR}=$ Relative density, ${ }^{2} \mathrm{~B}=$ Footing Width, ${ }^{3} \mathrm{H}=$ Pipe Depth, ${ }^{4} \mathrm{D}=$ Diameter of Pipe, ${ }^{5} \mathrm{PL}=$ Pipe Length, ${ }^{6} \mathrm{~L}=\mathrm{Geogrid}$ Length

${ }^{7} \mathrm{u}=$ Depth of Geogrid Layer 


\section{Results and Discussion}

The results of the above described testing program is illustrated in the next section, it should be mentioned that all bearing graphs that will be illustrated have been plotted with a huge number of points, as the data was recorded each 0.1 second increments.

\subsection{Test Repeatability and effect of relative density on strip footing bearing capacity}

In order to examine the repeatability of the results a testing program was conducted using only backfill soil with no geogrid reinforcement and without buried pipe. Two replicates were conducted at each compaction effort and the relative density of the soil was changed from $30 \%$ to $80 \%$. The Results of the two-replicates for each relative density are illustrated in Fig. 3. Increasing of relative density up to $80 \%$, have shown significant improvement in bearing capacities and initial stiffening compared to others, as well as decreasing in footing settlement at which failure occurred. Local shear failure phenomena were observed with relative densities less than 50\%, and general failure in higher relative densities. The variation between the two replicates was negligible with a maximum difference in results of two replicates were $9.4 \%$ for $40 \%$ relative density at s/B of 25. Moreover, as shown in Fig. 3, the trends and shapes of failures were also observed to be similar in each two replicates conducted. This figure verifies that the procedure followed could produce repeatable tests within the expected bounds of error with same apparatus. However, the behavior after failure is not expected to follow the same pattern for duplicate tests.

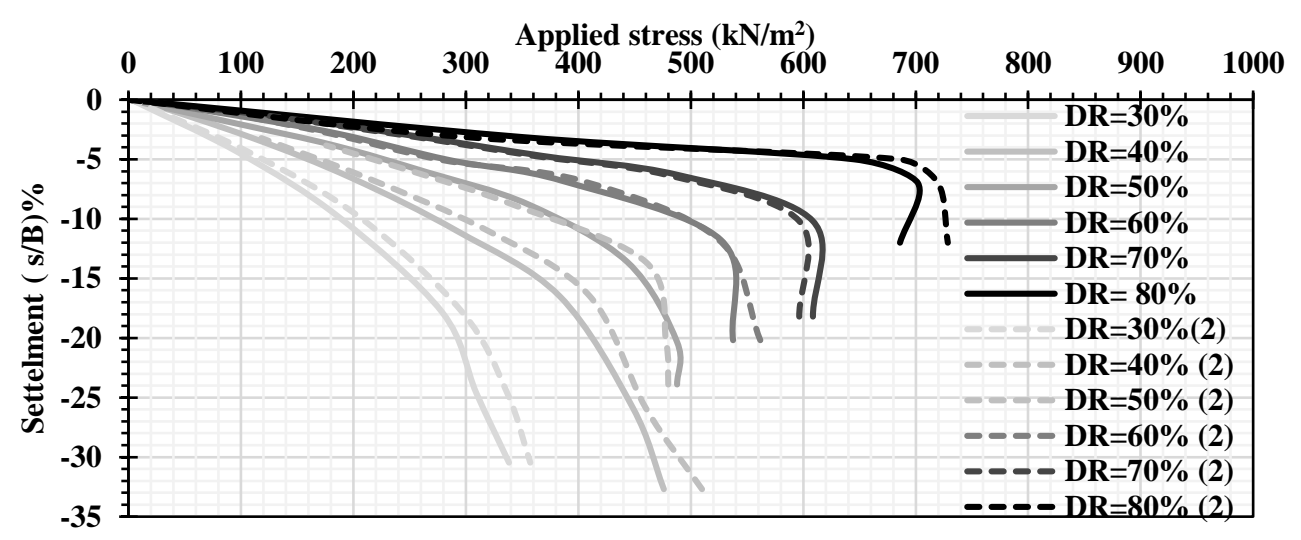

Fig. 3: Load Bearing with Normalized Settlement for Different Relative Densities.

\subsection{Effect of Compaction on Pipe Deflection}

In the second test series, a pipe was introduced with no geogrid reinforcement. Pipe deformation was observed during compaction process in order to assess the effect of the level of compaction on the pipe deformation. The pipe vertical deformation (y) increases with the increase in compaction effort as shown in Fig. 4. The deformation in the pipe increases till the compaction reach the pipe crown then the deformation stays constant. Ratio of pipe vertical deflection over the pipe diameter (y/D) reaches a value of $1.4 \%$ for the relative density of $80 \%$ and a value of $0.4 \%$ for relative compaction of $30 \%$. However, before loading was applied in further tests, the LVDTs were set to value of $0.0 \%$. 


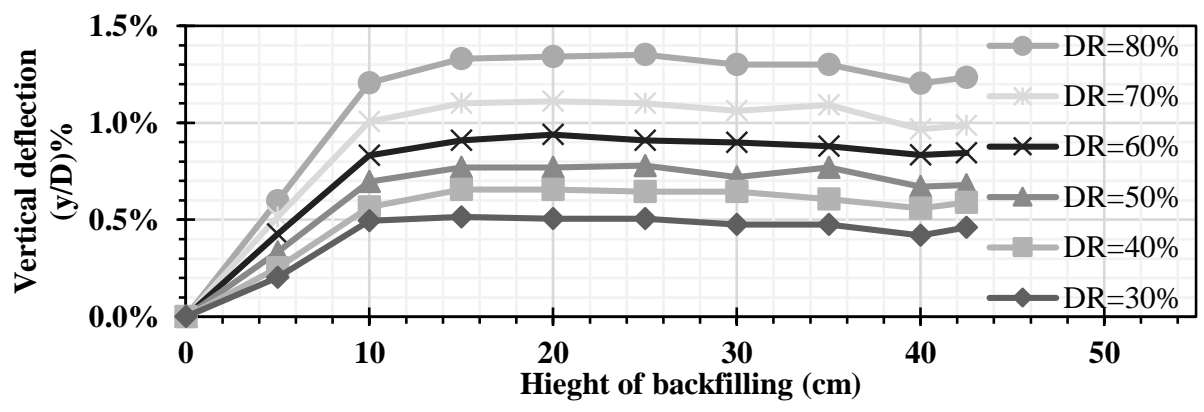

Fig. 4: Backfilling Height and its effect on vertical deflection of pipes.

\subsection{Effect of Compaction}

In the third test series, one layer of geogrid TriAx-150 was introduced in the backfill at variable depth. The backfill relative density was changed over a range from 50,60 and 70\% using depth. The geogrid location was varied with diameter ratios $(\mathrm{u} / \mathrm{D})$ of $0.075,0.113$ and 0.15 . These nine different combinations have been developed to optimize the depth of the geogrid layer and were loaded till failure. Results of applied stress plotted versus normalized settlement (s/D) where D is the pipe diameter are shown in Fig. 5(a). Significant increase in applied stress was generally observed comparing unreinforced backfill to reinforced backfill. Also, Reduction of surface settlement was observed for the reinforced backfill compared to unreinforced backfill. Moreover, the results suggest an optimum location of one layer of geogrid reinforcement at $\mathrm{u} / \mathrm{D}$ ratio of 0.11 . Fig $5 \mathrm{~b}$, shows the vertical deflection of pipe normalized with pipe dimeter (y/D) plotted versus the applied stress at the soil surface. These figure shows a significant reduction of pipe deflection due introduction of the geogrid reinforcement. Also, reduction in pipe vertical deformation was observed due to the increase in relative density of the backfill. A significant reduction was observed in pipe deflection for geogrid located at $\mathrm{u} / \mathrm{D}$ value of 0.113 .

(a)

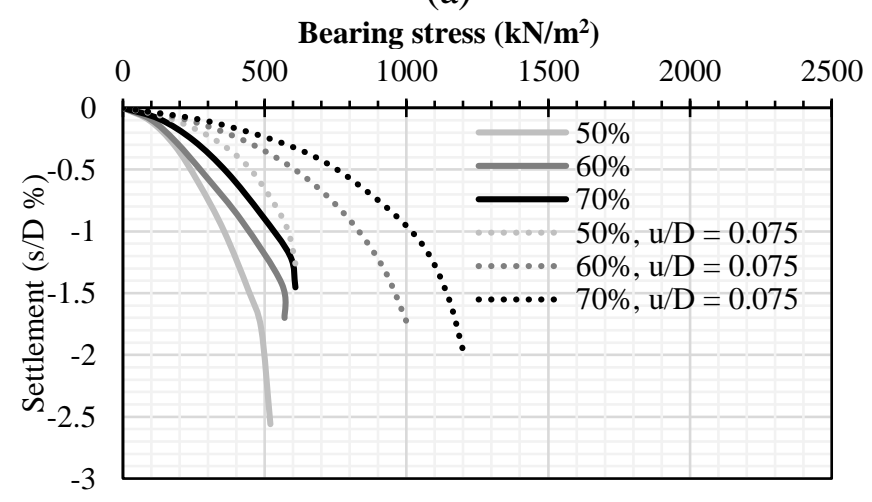

(b)

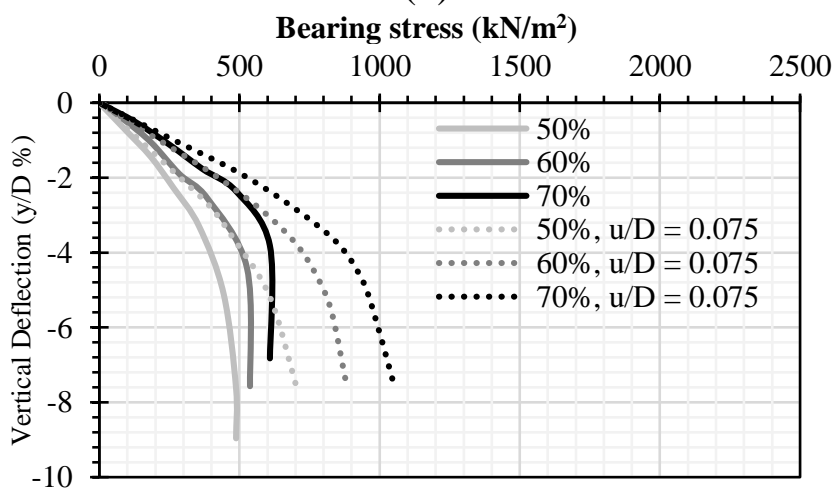



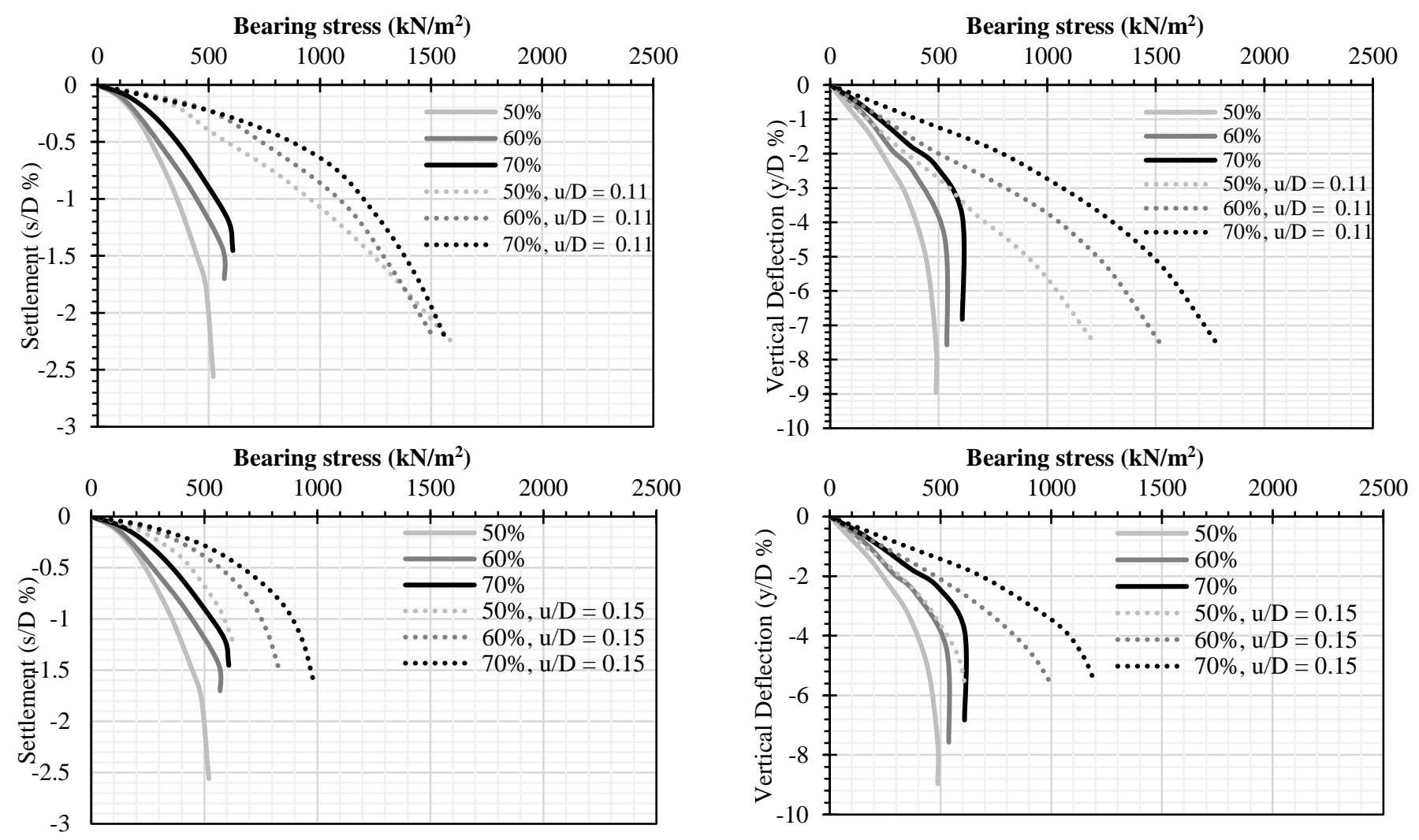

Fig. 5: a) Load-Settlement Curves, for different relative densities and u/D ratios, b) Load- and Pipe Deflection Curves, for different relative densities and $\mathrm{u} / \mathrm{D}$ ratios.

\subsection{Optimum Depth of One Layer Geogrid Reinforcement}

To better understand the improvements due to geogrid reinforcement chart was plotted for the surface settlement reduction factor (SRF) and vertical deflection reduction factor (DRF) versus the location of the geogrid normalized by the pipe diameter (d). The SRF \& DRF are defined as following:

$$
\begin{aligned}
& \mathrm{SRF}=\frac{\mathrm{s}_{\mathrm{r}}}{\mathrm{s}_{\mathrm{unr}}} \\
& \mathrm{DRF}=\frac{y_{r}}{y_{u n r}}
\end{aligned}
$$

Where $s_{u n r}$ and $s_{r}$ are the surface settlement of unreinforced and reinforced sand, respectively. Also $y_{u n r}$ and $y_{r}$ are the vertical deflection of pipes for unreinforced and reinforced sand respectively, at applied stress of $500 \mathrm{kPa}$. Fig. 6 shows results for $\mathrm{SRF}$ and DRF versus $\mathrm{u} / \mathrm{D}$ for the three different relative densities at different $\mathrm{u} / \mathrm{D}$ ratios. It can be observed that the increase in relative density resulted in a decrease in SRF and DRF, which means decreasing the settlement and vertical pipe deflection. The lowest values of SRF (0.22) was observed at u/D of 0.11 and relative density of $70 \%$. A minimum DRF value of 0.51 at relative density of $50 \%$, because the highest relative deflection of the $50 \%$ density is higher than higher ones. 


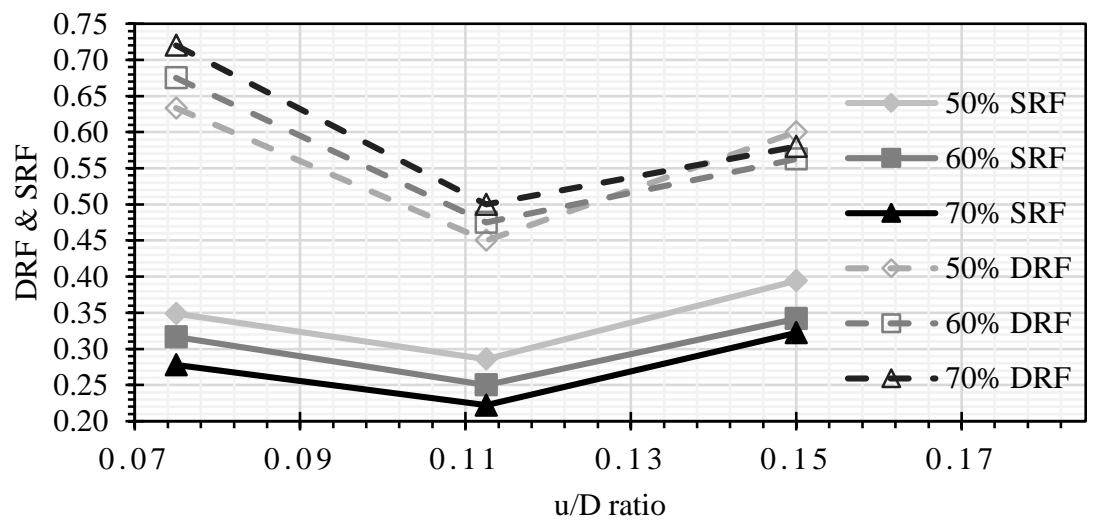

Fig. 6: Variation of DRF and SRF with $\mathrm{u} / \mathrm{D}$.

\section{Conclusion}

Surface Static loading may cause damage to buried pipelines, particularly at shallow depths. Damage is likely to be greatest when the buried pipe crosses the loading because of the layout of site. The deflection of such pipes under loading may cause severe damage issues in terms of supply or quality. In this study, three series of testing investigated the effect of compaction level on the geogrid reinforcement. The first set of testing have been used as quality control measure to check the repeatability of the testing procedure and the proposed procedure for the backfill compaction. As expected, surface settlement decreased with increasing the relative densities, while the bearing capacity increased. Local shear failure was observed in relative densities lower than 50\%, and general failure in higher relative densities. Also, results of the pairs of testing at the same levels of compaction revealed repeatability of the results in terms of surface settlement a maximum error of about $9 \%$. In the second series, a relative compaction of the backfill was changed over a wide range to investigate the effect of the backfill compaction on the pipe response. This testing series serves as a control for the geogrid reinforced backfill. Large scale tests have been done on Poorly graded sand (SP) and PVC pipes of $200 \mathrm{~mm}$ diameter. In this series, results have shown decreasing in pipe vertical deflection due to the increase in relative density. Finally, third series was conducted with one layer of geogrid located at varying depth from the surface. In this study, the effect of the backfill compaction effort on the optimum location of the geogrid was investigated. An optimum depth to diameter ratio of 0.11 was found to reduce the surface settlement with a factor of about $78 \%$ (SRF $=0.22)$ for a relative density of $70 \%$. Also, a reduction of $51 \%(\mathrm{DRF}=0.49)$ of pipe vertical deflection was observed for geogrid reinforced backfill at relative density of 50\%. In practice, it may be concluded that the performance of geogrid in this type of application is sensitive to the compaction level, so that the provision of a well-compacted soil beneath and above the geogrid is crucial for the protection of the buried pipe under reinforced with geogrids.

\section{Acknowledgements}

This research was supported by University of Sharjah, United Arab Emirates (Grant No. :1602040146). The authors would like to thank Engineers Kusi Al-Naser, Ahmed Shweiki, Mohamed Refaei and Rami Al-Sodi for their help in preparing the setup and machine operations. 


\section{References}

[1] Y. W. Choo, T. H. Abdoun, M. J. O'Rourke and D. Ha, "'Remediation for buried pipeline systems under permanent ground deformation," Soil Dynamics and Earthquake Engineering, vol. 27, no. 12, pp. 1043-1055.

[2] C. Rogers, P. Fleming and R. Talby, '"Use of Visual Methods to Investigate Influence of Installation Procedure on Pipe-Soil Interaction," Transportation Research Record: Journal of the Transportation Research Board, vol. 1541, Jan, pp. 76-85.

[3] D. Gruver, T. Masada, S. M. Sargand and B. Tarawneh, "Field Performance and Analysis of Large-Diameter HighDensity Polyethylene Pipe under Deep Soil Fill," Journal of Geotechnical and Geoenvironmental Engineering, vol. 131, no. 1, Jan, pp. 39-51.

[4] S. N. Moghaddas Tafreshi, O. Khalaj and M. Halvaee, '"Experimental study of a shallow strip footing on geogridreinforced sand bed above a void," Geosynthetics International, vol. 18, no. 4, pp. 178-195.

[5] M. A. El Sawwaf, '"Behavior of strip footing on geogrid-reinforced sand over a soft clay slope," Geotextiles Geomembranes, vol. 25, no. 1, pp. 50-60.

[6] K. Deb, S. Chandra and P.K. Basudhar, "'Settlement response of a multilayer geosynthetic-reinforced granular fillsoft soil system," Geosynthetics International, vol. 12, no. 6, pp. 288-298.

[7] E. C. Shin and B. M. Das, "Experimental study of bearing capacity of a strip foundation on geogrid-reinforced sand," Geosynthetics International, vol. 7, no. 1, pp. 59-71.

[8] S. G. Thallak, S. Saride and S. K. Dash, "'Performance of surface footing on geocell-reinforced soft clay beds," Geotech.Geol.Eng., vol. 25, no. 5, pp. 509.

[9] E. M. Palmeira and H. Andrade, "Protection of buried pipes against accidental damage using geosynthetics," Geosynthetics International, vol. 17, no. 4, pp. 228-241.

[10] M. X. Zhang, A. A. Javadi and X. Min, "'Triaxial tests of sand reinforced with 3D inclusions," Geotextiles Geomembranes, vol. 24, no. 4, pp. 201-209.

[11] S. N. Moghaddas Tafreshi and O. Khalaj, "'Laboratory tests of small-diameter HDPE pipes buried in reinforced sand under repeated-load," Geotextiles and Geomembranes, vol. 26, no. 2, pp. 145-163.

[12] ASTM Committee D-18 on Soil and Rock, "'Standard test methods for specific gravity of soil solids by water pycnometer," 2006.

[13] ASTM Committee D-18 on Soil and Rock, "'Standard test methods for maximum index density and unit weight of soils using a vibratory table," 2006.

[14] American Society for Testing and Materials, "'Standard test methods for minimum index density and unit weight of soils and calculation of relative density," 2006.

[15] American Society for Testing and Materials. Committee D18 on Soil and Rock, '"Standard test methods for particlesize distribution (gradation) of soils using sieve analysis," 2004.

[16] ASTM Committee D-18 on Soil and Rock, "Standard practice for classification of soils for engineering purposes (Unified Soil Classification System)," 2011.

[17] D.3. ASTM, "Standard test method for direct shear test of soils under consolidated drained conditions," D3080/D3080M.

[18] ASTM D2321-11, "Standard Practice for Underground Installation of Thermoplastic Pipe for Sewers and Other Gravity-Flow Applications," Ann Book ASTM Standards, vol. 8, pp. 1-10.

[19] M. T. Omar, B. M. Das, V. K. Puri and S. C. Yen, "Ultimate bearing capacity of shallow foundations on sand with geogrid reinforcement," Canadian Geotechnical Journal, vol. 30, no. 3, pp. 545-549. 